\title{
Overexpression in Neurons of Human Presenilin-1 or a Presenilin-1 Familial Alzheimer Disease Mutant Does Not Enhance Apoptosis
}

\author{
Sherry Bursztajn, ${ }^{1}$ Richard DeSouza, ${ }^{2}$ Donna L. McPhie, ${ }^{3}$ S. A. Berman, ${ }^{1}$ Junichi Shioi, ${ }^{4}$ \\ Nikolaos K. Robakis, ${ }^{4}$ and Rachael L. $\mathrm{Neve}^{3}$ \\ ${ }^{1}$ Department of Psychiatry and Program in Neuroscience, Harvard Medical School, Belmont, Massachusetts 02478, \\ 2Department of Biology, Massachusetts Institute of Technology, Cambridge, Massachusetts 02139, ${ }^{3}$ Department of \\ Genetics, Harvard Medical School, McLean Hospital, Belmont, Massachusetts 02478, and ${ }^{4}$ Department of Psychiatry \\ and Fishberg Research Center for Neurobiology, Mount Sinai School of Medicine, New York, New York 10029
}

Programmed cell death, or apoptosis, has been implicated in Alzheimer's disease (AD). DNA damage was assessed in primary cortical neurons infected with herpes simplex virus (HSV) vectors expressing the familial Alzheimer's disease (FAD) gene presenilin-1 (PS-1) or an FAD mutant of this gene, A246E. After infection, immunoreactivity for PS-1 was shown to be enhanced in infected cells. The infected cells exhibited no cytotoxicity, as evaluated by trypan blue exclusion and mitochondrial function assays. Quantitative analysis of cells that were immunohistochemically labeled using a Klenow DNA fragmentation assay or the TUNEL method revealed no enhancement of apoptosis in PS-1-infected cells. This result was confirmed using assays for chromatin condensation and for DNA fragmentation. Expression of PS-1 protected against

Cell death can occur by two morphologically and biochemically distinct pathways: necrosis and apoptosis. These two pathways are not mutually exclusive, and both types of death have been observed in the brain in Alzheimer's disease. Necrosis is characterized by cell swelling, rapid lysis of the cellular membrane, and expulsion of intracellular organelles. In contrast, in apoptosis, or programmed cell death, nuclear changes and alterations in chromatin material are produced by a series of well orchestrated cellular events that require RNA and protein synthesis. Apoptotic cells show morphological changes that include condensation and fragmentation of heterochromatin, membrane blebbing, loss of the nuclear envelope, and cellular fragmentation into apoptotic bodies, whereas most of the organelles remain intact. During apoptosis, a specific endonuclease cleaves the DNA between nucleosomes into characteristic fragments that form a ladder pattern when separated on an agarose gel, whereas in necrosis, DNA becomes degraded randomly.

Familial Alzheimer's disease (FAD) can be caused by muta-

\footnotetext{
Received April 23, 1998; revised Sept. 11, 1998; accepted Sept. 11, 1998.

This work was partly supported by the Massachusetts Alzheimer's Disease Research Center (S.B.), by the Alzheimer Disease and Related Disorders Association (N.K.B.), and by National Institute on Aging Grants AG12954 (R.L.N.) and AG08200 (N.K.R.). We thank Dr. Robert Coopersmith for invaluable help with the figures.

Correspondence should be addressed to Dr. Sherry Bursztajn at her present address: Biomedical Research Institute F6-21, Louisiana State University Medical Center, 1501 Kings Highway, Shreveport, LA 71130, E-mail: sbursz@lsumc.edu, or Dr. Rachael L. Neve at her present address: MRC, McLean Hospital, 115 Mill Street, Belmont, MA 02478. E-mail: neve@helix.mgh.harvard.edu

Dr. Berman's present address: Louisiana State University Medical Center, Shreveport, LA 71130.

Copyright (C) 1998 Society for Neuroscience $\quad 0270-6474 / 98 / 189790-10 \$ 05.00 / 0$
}

induction of apoptosis in the cortical neurons by etoposide or staurosporine. The specificity of this phenotype was demonstrated by the fact that cortical cultures infected with recombinant HSV vectors expressing the amyloid precursor protein (APP-695) showed, in contrast, a significant increase in the number of apoptotic cells and an increase in DNA fragmentation for all parameters tested. Our results indicate that overexpression of wild-type or A246E mutant PS-1 does not enhance apoptosis in postmitotic cortical cells and suggest that the previously reported enhancement of apoptosis by presenilins may be dependent on cell type.

Key words: apoptosis; neurodegeneration; presenilin; amyloid precursor protein; DNA fragmentation; Alzheimer's disease

tions in the amyloid precursor protein (APP) gene or in the presenilin genes PS-1 and PS-2. Overexpression in neuronal cells of FAD APP cDNAs that are mutated at V642 (the "London" mutation) has been shown to cause double-stranded DNA breaks (Yamatsuji et al., 1996 a,b), one feature of the programmed cell death termed apoptosis (Bredesen, 1995; Thompson, 1995). Recently, two genes that cause early onset FAD, S182 [presenilin-1 (PS-1)] and STM2 [presenilin-2 (PS-2)], have been identified (Levy-Lahad et al., 1995; Rogaev et al., 1995; Sherrington et al., 1995). Approximately half of inherited AD cases are caused by mutations in these two genes. It has been reported that overexpression of these genes in transfected cell lines can cause apoptosis (Janicki and Monteiro, 1997) or result in an increased susceptibility to apoptosis (Deng et al., 1996; Guo et al., 1996, 1997, 1998; Wolozin et al., 1996). However, it is not known whether the overexpression of wild-type or FAD mutant PS-1 in postmitotic cortical neurons results in DNA damage or apoptosis. To gain a better understanding of the role of these genes in neuronal apoptosis, we have used herpes simplex virus (HSV) vectors to overexpress wild-type and mutant PS- 1 cDNAs in primary cortical neurons. We show here that apoptosis is not enhanced in neuronal cells infected with these vectors, and we suggest that the previously reported enhancement of apoptosis by presenilins may be cell type-dependent.

\section{MATERIALS AND METHODS}

Generation of recombinant $H S V$ vectors and infection of primary mouse cortical cultures. The human PS-1 cDNA was obtained by PCR screening (Chow et al., 1996) of a human fetal brain cDNA library. The QuikChange mutagenesis kit (Stratagene, La Jolla, CA) was used to 

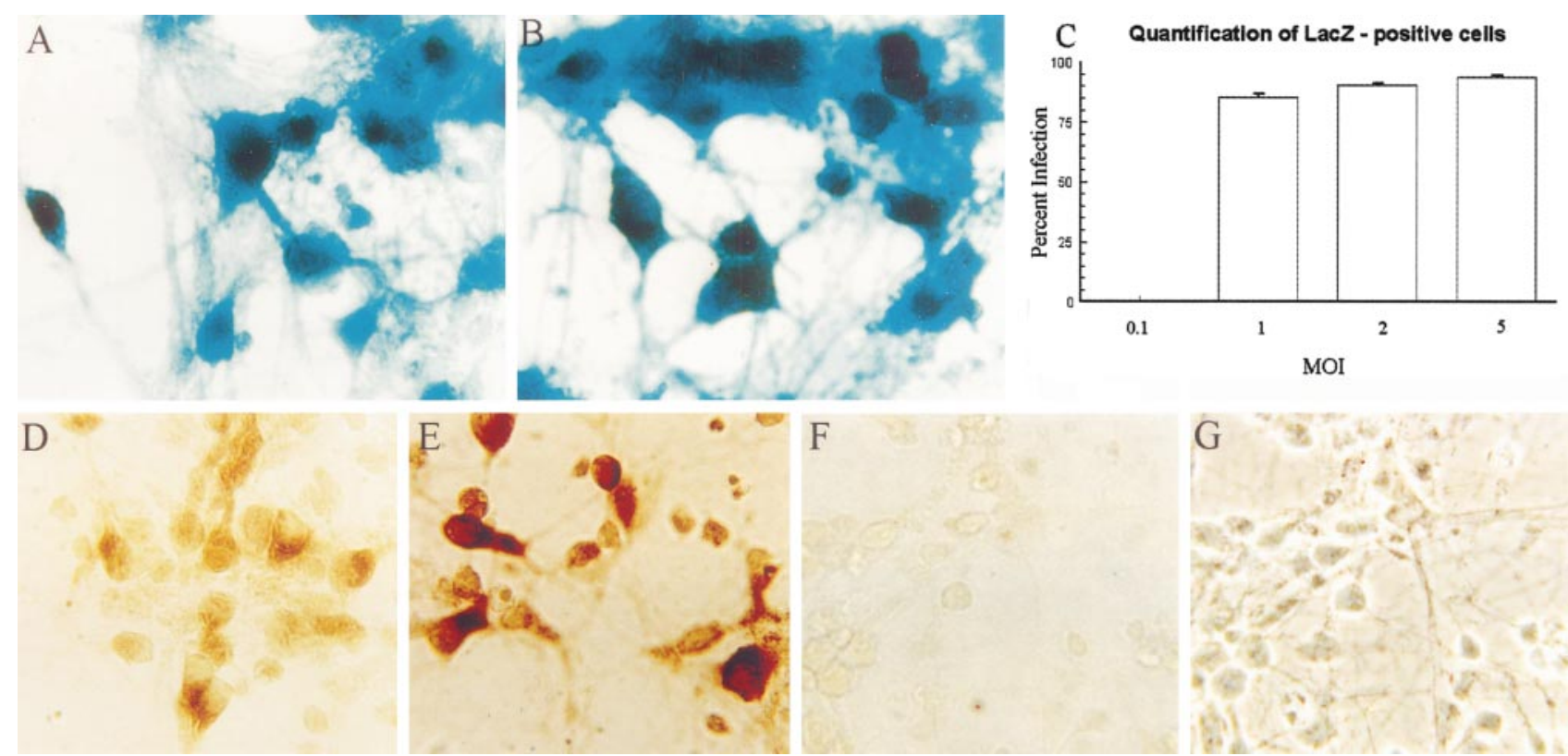

$\mathrm{F}$

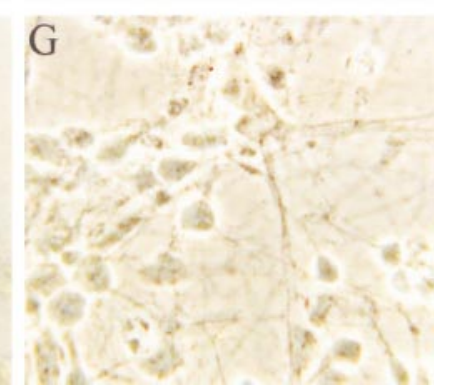

Figure 1. High levels of efficiency of expression are seen after recombinant HSV infection of cortical neurons. Mouse cortical neurons were maintained in Neurobasal medium with B27 supplement and $1 \%$ horse and fetal bovine serum. At 5 DIV, cells were infected with recombinant HSV viruses at a range of moi. $A-C, \mathrm{HSV} / \mathrm{Lac}$ infection of primary cortical neurons at an moi of $2(A)$ or $5(B)$. Twelve hours after infection, cells were fixed and processed for $\beta$-galactosidase activity (blue cells). $C$, LacZ-positive and total cells were counted in 10 random fields for each moi, and the percentage of blue cells was determined. The data are expressed as the average \pm SE of 10 microscopic fields, with a total of $553-641$ cells counted for each moi. $D-G$, HSV/myc-PS-1 infection of primary cortical neurons at an moi of $1(D)$ or $5(E)$. The brown reaction product delineates myc immunoreactivity in infected cells. $F, G$, Uninfected neurons incubated with Myc antibody and processed in parallel with the cells shown in $D$ and $E$. $D-F$ are bright-field images. $G$ is a phase-contrast image of $F$. Scale bar, $25 \mu \mathrm{m}$.

generate the A246E mutation in the PS-1 cDNA. The presence of the mutation was verified by DNA sequence analysis.

We prepared replication-defective HSV vectors expressing the wildtype (HSV/PS-1) and mutant (HSV/A246E-PS-1) human PS-1 cDNAs and Escherichia coli $\beta$-galactosidase (HSV/Lac; negative control) in the expression vector pHSVPrpUC as described (Carlezon et al., 1997). Some experiments used an HSV vector expressing N-terminal myc epitope (EQKLISEEDL)-tagged PS-1 cDNA. HSV/APP-695 was prepared as described (McPhie et al., 1997). The titer of the helper virus component of each stock was $1-1.2 \times 10^{6}$ plaque-forming units $(\mathrm{pfu}) / \mathrm{ml}$ on 2-2 cells. The titer of the recombinant virus component of each stock, as assayed by expression of the exogenous gene in PC12 cells, was consistently $3 \times 10^{7}$ infectious units (iu) $/ \mathrm{ml}$.

Cortices from embryonic day 18 (E18) mice (Charles River, Wilmington, MA) were dissociated mechanically in serum-free Neurobasal medium supplemented with B27 (Life Technologies, Gaithersburg, MD). Cells were plated at a density of $3 \times 10^{6}$ cells $/ \mathrm{ml}$ in poly-L-ornithinecoated $35 \mathrm{~mm}$ culture dishes and were maintained in Neurobasal medium supplemented with B27 and 1\% each fetal bovine and horse serum. Cells were infected with HSV recombinants $5 \mathrm{~d}$ after plating. Immunoblots (see Fig. 2) to demonstrate levels of expression of the HSV recombinant genes used primary cultures from E18 rat embryos that were generated and maintained under the same conditions as the mouse primary neuronal cultures.

Determination of efficiency of expression of HSV recombinants. Efficiency of infection of the control virus HSV/Lac was determined using $\mathrm{X}$-gal histochemistry to detect cells expressing $\beta$-galactosidase (LacZ). Twenty-four hours after infection, the percentage of LacZ-positive cells was determined by comparing the number of blue cells with the total number of cells in 10 random microscope fields for each multiplicity of infection (moi).

Immunocytochemistry with a monoclonal antibody to the myc tag (9E10; American Type Culture Collection) was used to determine the efficiency of infection of neurons by HSV/myc-PS-1. Twenty-four hours after infection, the cells were fixed with $4 \%$ paraformaldehyde at room temperature for $20 \mathrm{~min}$, washed with PBS, and incubated with a 1:50 dilution of the primary antibody. The myc epitope was localized with a secondary antibody conjugated to horseradish peroxidase (HRP), which

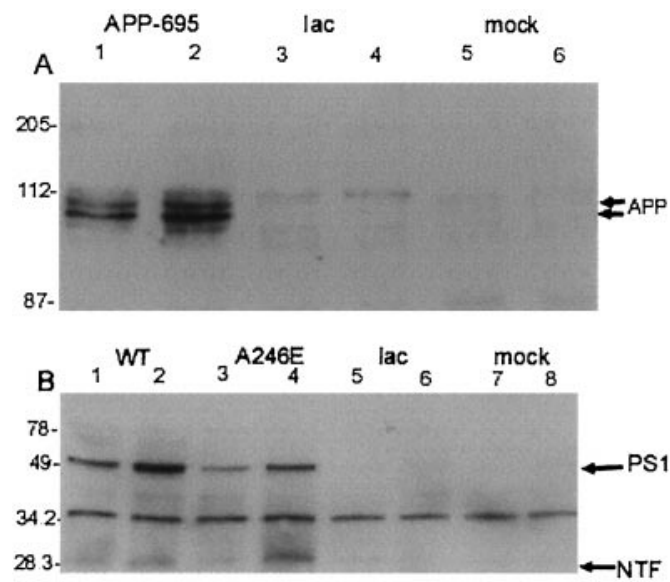

Figure 2. PS-1 and APP-695 overexpression in cortical cells. Primary neuronal cells prepared from E18 rat cortex were infected with recombinant HSV expressing APP-695, wild-type PS-1, or A246E-mutant PS-1, or were mock-infected. $A$, Cell extracts from cortical neurons that were infected with HSV/APP-695 (lanes 1 and 2, moi $=0.5$ and 1, respectively) or HSV/Lac (lanes 3 and 4 , moi $=0.5$ and 1 , respectively) or that were mock-infected (lanes 5 and 6 ) were analyzed by immunoblot analysis using 22C11 (Boehringer Mannheim). The cluster of bands around $110 \mathrm{kDa}$ represent immature and mature (differentially glycosylated) APP-695. $B$, Cell extracts from cortical neurons that were infected with HSV/PS-1 (lanes 1 and 2, moi $=0.5$ and 1, respectively), HSV/A246E-PS-1 (lanes 3 and 4 , moi $=0.5$ and 1 , respectively), or HSV/Lac (lanes 5 and 6 , moi $=0.5$ and 1 , respectively) or that were mock-infected (lanes 7 and 8 ) were analyzed by immunoblot analysis using the rabbit polyclonal 347 antiserum, against PS-1 amino acids 2-12. Full-length PS-1 and the N-terminal fragment $(N T F)$ are immunodetected at 49 and $29 \mathrm{kDa}$, respectively. The band at 34 $\mathrm{kDa}$ probably is nonspecific. Detection of the full-length PS- 1 bands was inhibited by the cognate peptide and was heat-sensitive (data not shown). At the exposure times used, endogenous full-length PS-1 was not detected. 

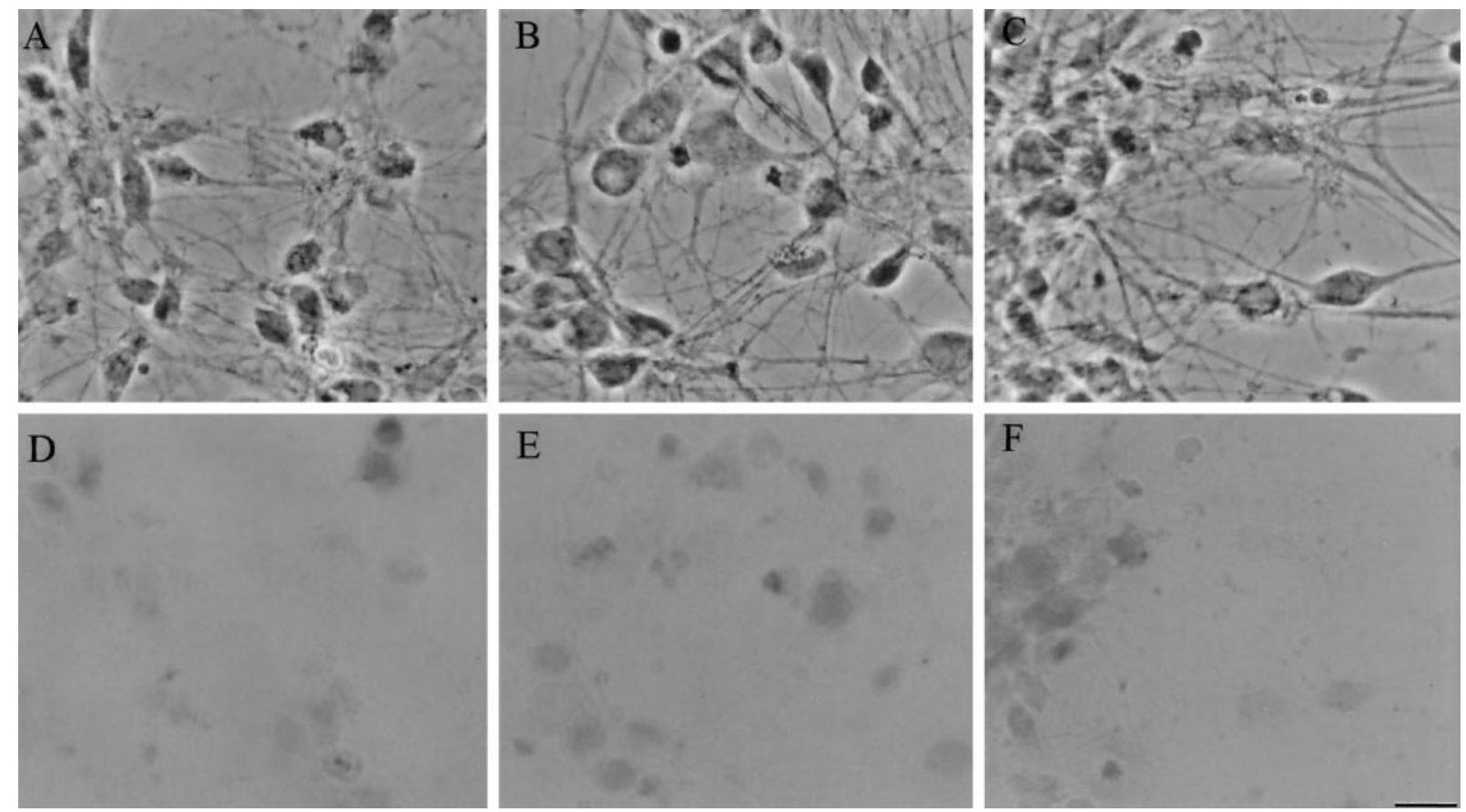

Figure 3. Cortical neurons infected with HSV/PS-1 $(A, D)$, HSV/A246E-PS-1 $(B, E)$, or HSV/Lac $(C, F)$ at an moi of 2 are viable. Twenty-four hours after infection, neurons were tested for exclusion of trypan blue. All HSV-infected neurons showed exclusion of trypan blue. $A-C$ are phase-contrast images. $D-F$ are bright-field images.

was visualized by incubating the cells in the 3,3'-diaminobenzidine (DAB) substrate for 5 min. Cells on coverslips were rinsed with PBS, mounted onto glass microscope slides using 90\% glycerol in PBS, and viewed with bright-field optics.

Immunoblot analysis of APP-695 and PS-1 expression in infected neurons was performed as described (Elder et al., 1996). For APP-695 detection, $20 \mu \mathrm{g}$ of protein was loaded into each lane of a $7 \%$ Tris-glycine gel. The mouse monoclonal anti-APP antibody 22C11 (Boehringer Mannheim, Indianapolis, IN) was used at a 1:1000 dilution. For PS-1 detection, $40 \mu \mathrm{g}$ of protein was loaded into each lane of a $10-20 \%$ Tris-tricine gel. The rabbit polyclonal 347 antiserum, against PS-1 amino acids $2-12$, was used at a 1:10,000 dilution. The blots were processed using the SuperSignal immunodetection system (Pierce, Rockford, IL).

Cell viability assays were performed to determine whether the HSV viruses affected cell survival. Cell viability was measured both by metabolic conversion of tetrazolium salt into formazan salt using a Cell Titer 96 Assay Kit (Promega, Madison, WI) and by using a trypan blue exclusion test.

Detection of DNA fragmentation using a photometric enzyme immunoassay. The presence of cytoplasmic histone-associated DNA fragments (mononucleosomes and oligonucleosomes) was quantitatively determined after induced cell death via Cell Death Detection ELISA (Boehringer Mannheim). Cells were ruptured in lysis buffer, vortexed, and incubated for $30 \mathrm{~min}$. The lysate was centrifuged at $200 \times g$ for $10 \mathrm{~min}$, after which the supernatant was transferred into wells of a streptavidincoated microtiter plate. An immunocomplex consisting of anti-histonebiotin (a biotinylated mouse monoclonal antibody, which bridges the histone component of the nucleosomes and the streptavidin coat on the plates) and anti-DNA-POD (a peroxidase-conjugated mouse monoclonal antibody, which reacts with the DNA component of the nucleosomes)

Figure 4. HSV-mediated expression of wild-type or mutated presenilins does not affect neuronal survival. Neurons were infected in parallel with HSV expressing wild-type PS-1, A246 PS-1, or LacZ, or vehicle only (Mock) at moi ranging from 0.1 to 5 . Survival was measured by metabolic conversion of tetrazolium salt into formazan salt using a Cell Titer 96 Assay Kit. $A$, Twelve hours after infection; $B, 24 \mathrm{hr}$ after infection; $C, 72$ $\mathrm{hr}$ after infection. A representative result from one of three independent experiments is shown. Each value is the average of three different wells, with error bars representing the range.
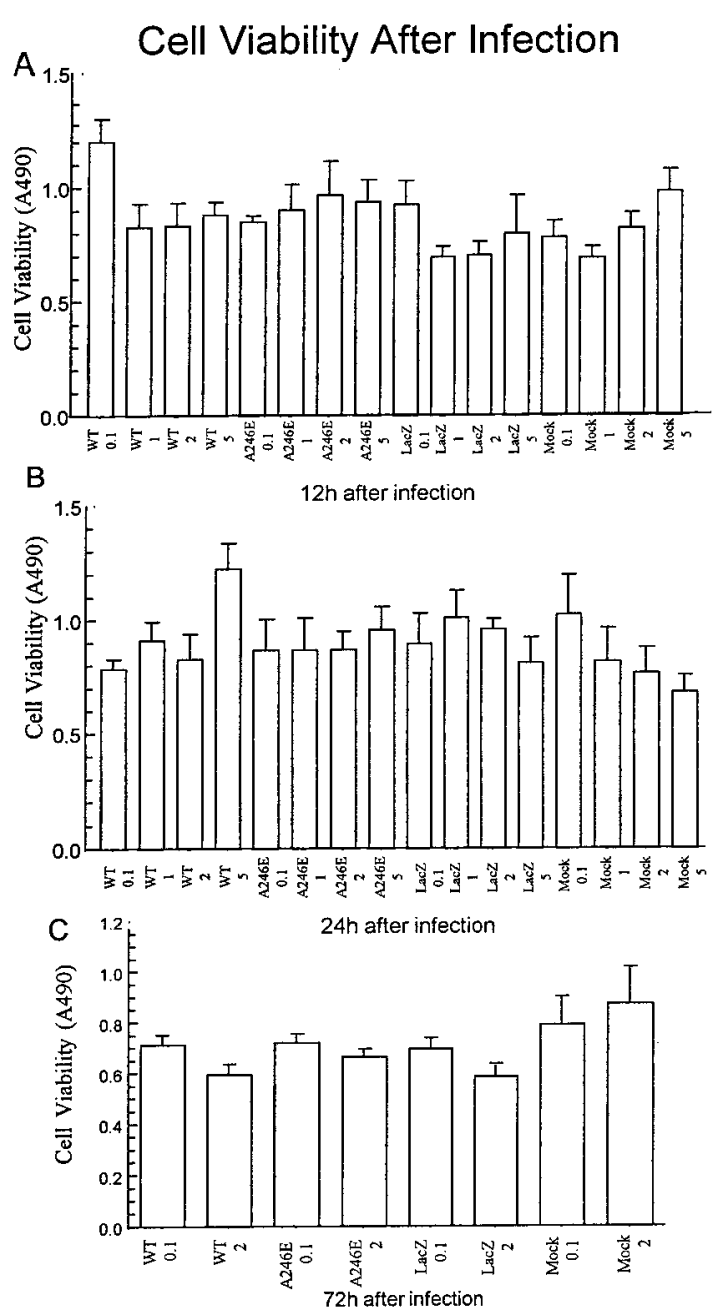

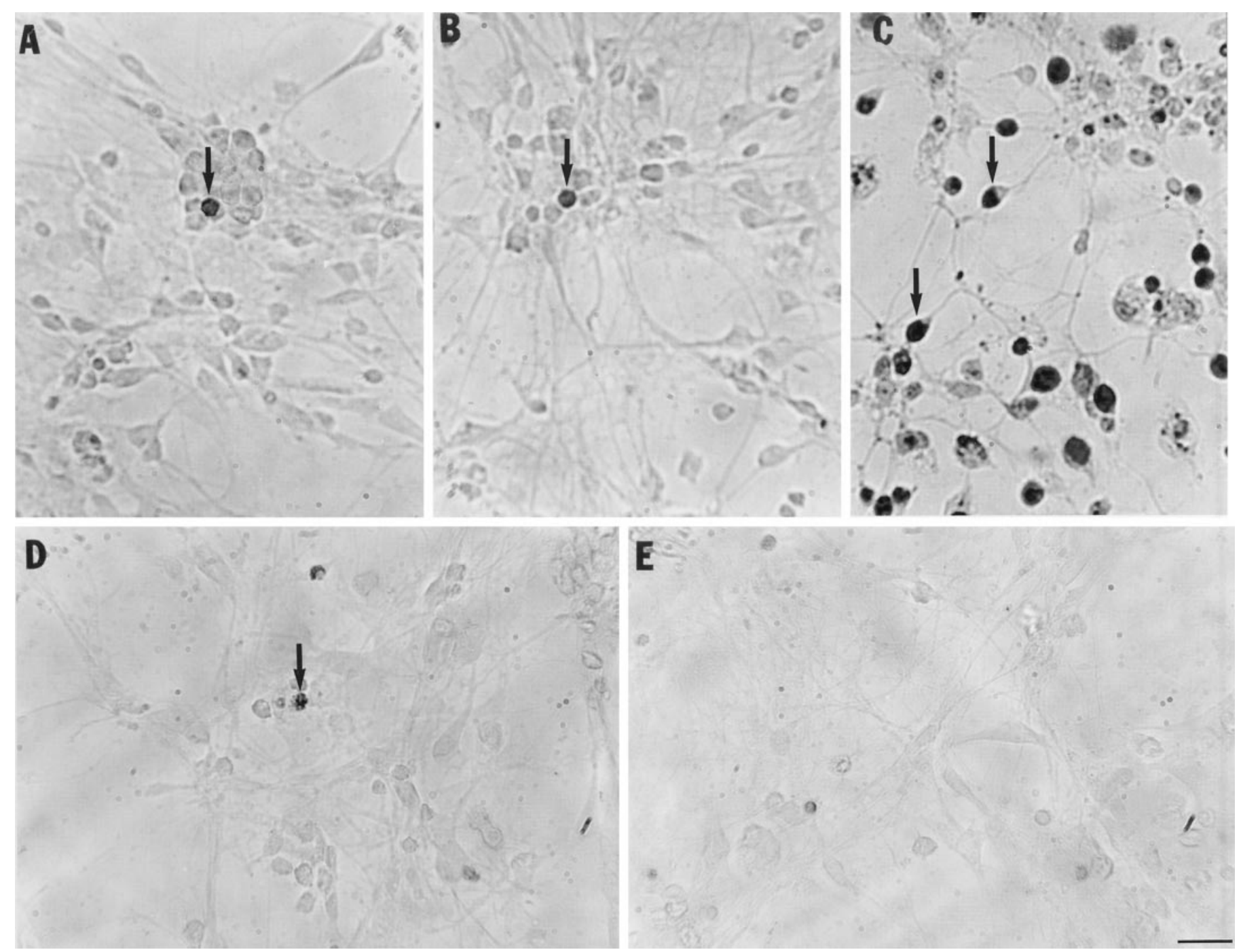

Figure 5. Single-stranded DNA breaks in cells of recombinant HSV-infected cultures were assessed using a Klenow assay. The dense reaction product (arrows) identifies apoptotic nuclei. Control cells incubated without the Klenow enzyme give negative results (no staining). Cortical cultures infected for $24 \mathrm{hr}$ at an moi of 2 with HSV/PS-1 $(A)$ or HSV/A246E-PS-1 $(B)$ show very few apoptotic nuclei. Cultures infected under the same conditions with HSV/APP-695 $(C)$ show numerous apoptotic nuclei. $D$, LacZ-infected cells; $E$, mock-infected cells.

was added to the plate, which was incubated at room temperature for 2 hr. The plates were washed to remove unbound antibodies, and the amount of histone-associated DNA fragments was quantified by analysis of the POD retained in the immunocomplex using a $2,2^{\prime}$-azino-di(3ethylbenzthiazolin-sulfonate) substrate, which was detected photometrically at a wavelength of $405 \mathrm{~nm}$.

Detection of DNA strand breaks using a Klenow fragment end-labeling technique. An alternative method of detecting DNA fragmentation involves histochemical labeling of exposed 3'-OH ends of the DNA using the FragEL-Klenow DNA Fragmentation Detection kit (Oncogene Research Products). Cultured cells on coverslips were fixed as described previously (Didier et al., 1996), washed, incubated in TBS for $15 \mathrm{~min}$ at room temperature, permeabilized with proteinase $\mathrm{K}$, and treated with $\mathrm{H}_{2} \mathrm{O}_{2}$ to inactivate endogenous peroxidases. The cells were incubated in a humidified chamber at $37^{\circ} \mathrm{C}$ for $1.5 \mathrm{hr}$ with biotinylated deoxynucleotides and Klenow enzyme, washed, and incubated with streptavidin$\mathrm{HRP}$, which was then visualized using DAB as substrate. Coverslips were mounted onto glass slides in $90 \%$ glycerol/PBS and were viewed with bright-field microscopy.

Detection of DNA double-strand breaks using the TUNEL in situ apoptosis assay. The TUNEL method (Gavrieli et al., 1992), which detects dioxigenin-labeled genomic DNA in situ using a modified terminal transferase dUTP nick end labeling (TUNEL) technique, was used to detect DNA double-strand breaks. The procedure was performed as described previously (Didier et al., 1996), using an Apoptag in situ apoptosis detection kit (Oncor).

Detection of apoptotic nuclear morphology using bisbenzimide. Bisbenzimide binds to and allows visualization of chromatin. Bisbenzimide $(1 \mu \mathrm{g} / \mathrm{ml})$ was added to the medium in which the fixed cells on coverslips were mounted onto glass slides, and cells were viewed with fluorescent microscopy to visualize the nuclear morphology, as described previously (Bruner and Bursztajn, 1986; Didier et al., 1996). The number of apoptotic nuclei, which appear smaller than normal and in which the chromatin appears condensed, were counted and compared with the total number of cells in 10 random fields for each moi.

Isolation of nuclear and cytoplasmic DNA from cultures infected with $H S V$ recombinants. Nuclear and cytoplasmic DNA was purified from three $35 \mathrm{~mm}$ dishes per sample of infected neurons, $24 \mathrm{hr}$ after infection, as described by Greenberg and Ziff (1984). After electrophoresis of the DNAs on agarose gels, they were transferred to Biotrans membrane (ICN Biochemicals, Costa Mesa, CA) and probed with radiolabeled total mouse DNA to increase the sensitivity of detection of DNA fragmentation.

Induction of apoptosis. Twelve hours after infection with HSV vectors, cells were exposed to $20 \mu \mathrm{M}$ etoposide or $1 \mu \mathrm{M}$ staurosporine for $5 \mathrm{hr}$. DNA fragmentation was detected using the photometric enzyme immunoassay described above. 


\section{Quantification of Apoptotic Cells}

\section{with Klenow DNA Fragmentation Assay}

A

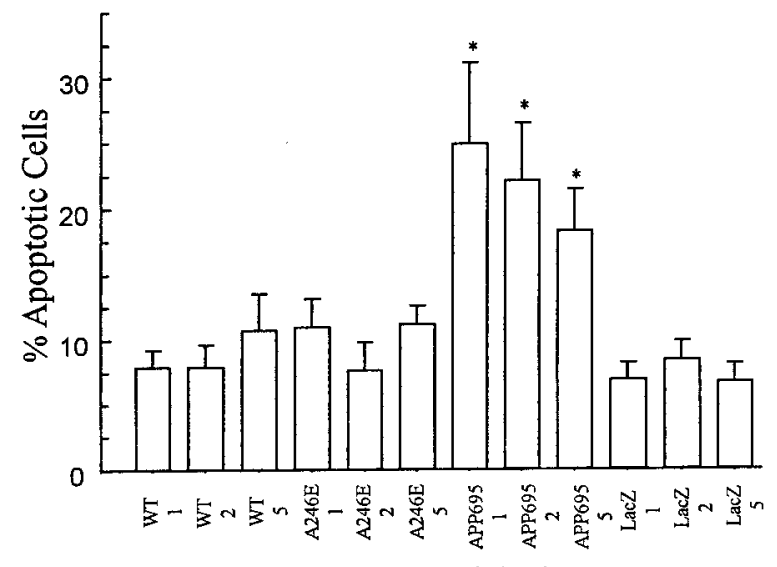

B

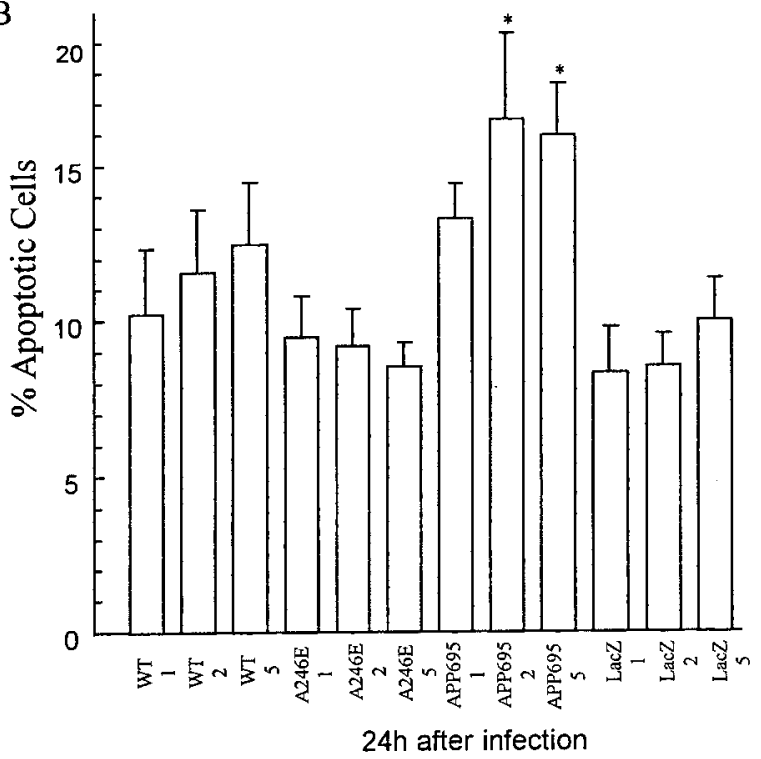

Figure 6. Quantification of the data shown in Figure 5 shows that overexpression of wild-type or A246E-mutant PS-1 does not enhance apoptosis in cortical cells, as measured with a Klenow DNA fragmentation assay. However, cells infected with HSV/APP-695 show a significant increase $(p<0.05$; Bonferroni multiple $t$ test $)$ in percentage of apoptotic cells. Cortical cells were infected as described in the legend to Figure 5. The total number of cells and the number of apoptotic cells were counted in 10 random fields, and the number of apoptotic cells was expressed as a percentage of the total cells counted. The results are the average \pm SEM. A total of 200-300 cells were counted for each moi. * denotes a significant $(p<0.05)$ difference in the percentages of apoptotic cells in HSV/APP695-infected cultures versus HSV/Lac-infected cultures. $A$, Twelve hours after infection; B, $24 \mathrm{hr}$ after infection.

\section{RESULTS}

\section{Determination of optimal efficiency of infection with recombinant HSV}

HSV/Lac, expressing the E. coli $\beta$-galactosidase gene, was used to determine the optimal conditions for gene transfer into the mouse cortical neurons. E17-18 neurons were infected with HSV/Lac at $5 \mathrm{~d}$ in vitro (DIV) using a range of moi from $0.1-5.0$ as described
Detection of DNA Fragmentation with a Photometric Enzyme-Immunoassay

A
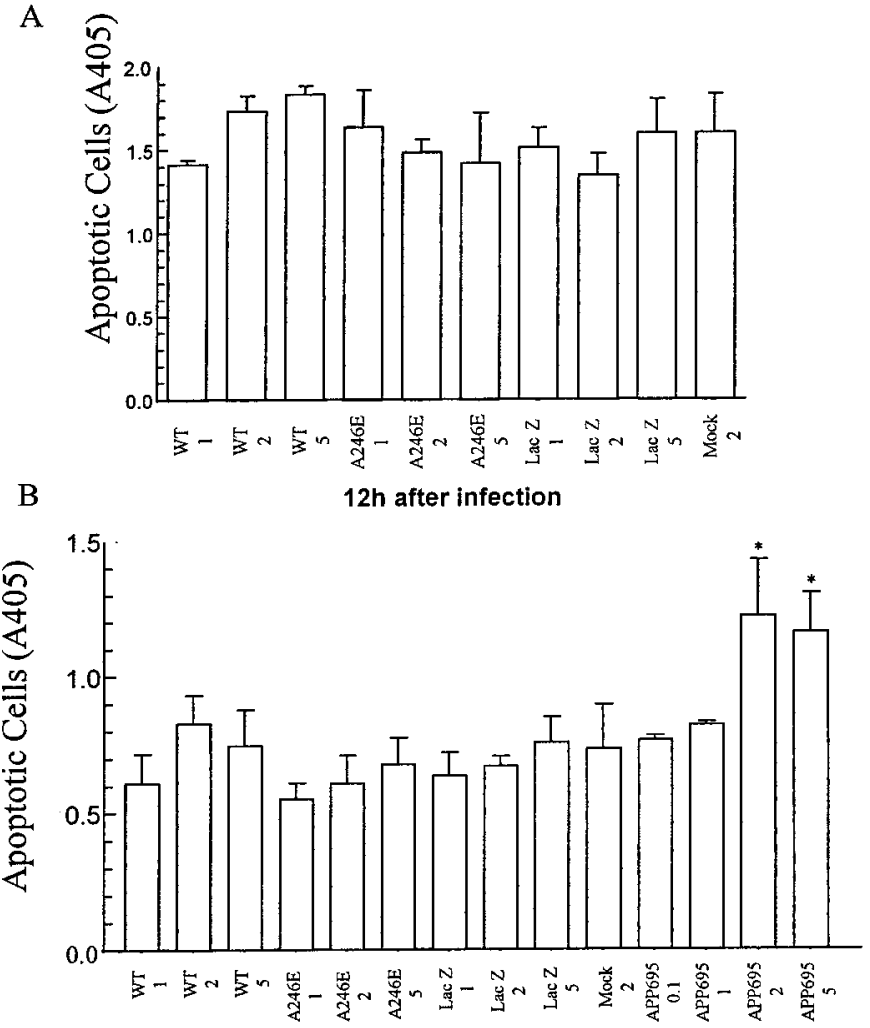

$24 \mathrm{~h}$ after infection

Figure 7. Quantification of apoptosis using a DNA fragmentation enzyme-immunoassay (Cell Death Detection ELISA), which detects histone-associated DNA fragments that are generated during the internucleosomal degradation of genomic DNA that occurs in apoptosis. Neurons were infected in parallel with HSV/PS-1, HSV/A246E-PS-1, HSV/APP-695, or HSV/Lac, or vehicle only (mock) at moi ranging from 1 to 5 . Samples were analyzed photometrically at $405 \mathrm{~nm}$, using substrate solution as a reference blank. Only neurons infected with HSV/APP-695 show significant changes in DNA fragmentation. $A$, Twelve hours after infection; $B, 24 \mathrm{hr}$ after infection. Results are the average of three different wells; error bars represent range.

(McPhie et al., 1997). Twelve hours after infection, X-gal histochemistry was performed to visualize cells expressing the $\beta$-galactosidase transgene. Infection with $\mathrm{HSV} / \mathrm{Lac}$ at an moi of 2 (Fig. $1 A$ ) yielded an efficiency of expression that was very near that of cultures infected with HSV/Lac at an moi of 5 (Fig. 1B). Quantitation of $\beta$-galactosidase-positive cells shows that at an moi of 0.1 almost no cells expressing LacZ were detected, whereas at 1,2 , and 5 moi, 85,90 , and $95 \%$, respectively, of cells were lacZ positive (Fig. 1C).

A similar efficiency of expression was seen when the cultures were infected with HSV/myc-PS-1, expressing PS-1 with an $\mathrm{N}$-terminal myc tag (Fig. $1 D-G$ ). Cells were infected with HSV expressing myc-PS-1, and the myc tag was immunodetected with the 9E10 monoclonal antibody, using DAB as the chromogen. The majority of cells in cultures infected with HSV/myc-PS-1 (Fig. 1D,E) displayed myc immunoreactivity. The myc immunoreactivity was specific, in that uninfected neurons incubated with the 9E10 antibody and processed simultaneously with cells shown in Figure $1 D, E$ show virtually no immunoreactivity (Fig. $1 F, G$ ). 

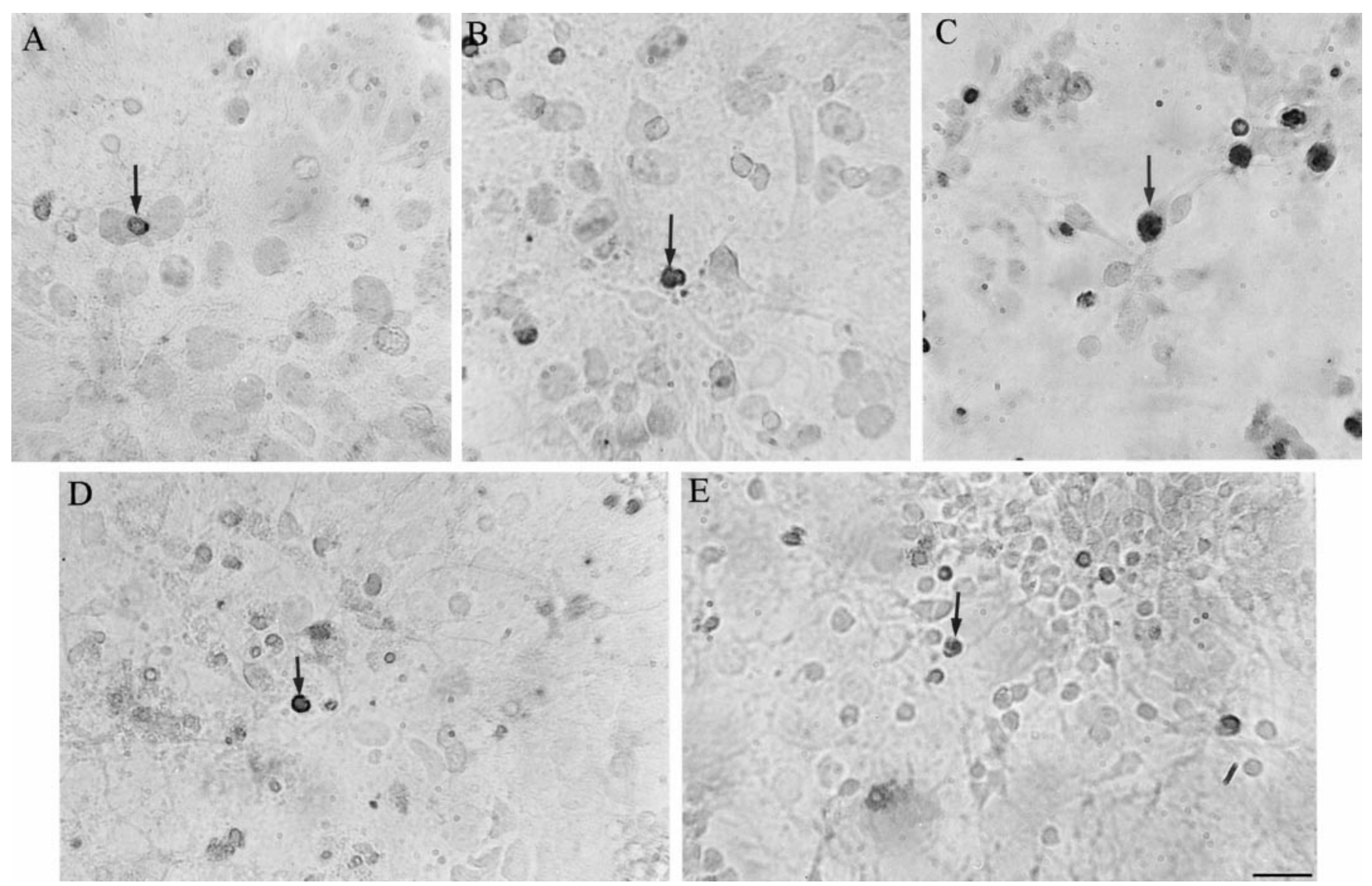

Figure 8. Overexpression of wild-type or A246E-mutated PS-1 does not enhance apoptosis in cortical cells, as detected with a TUNEL method (Apoptag). This method, in contrast to the Klenow fragmentation assay, detects primarily double-stranded DNA breaks. Cortical cells were infected as described in the legend to Figure 5. Cells were fixed and incubated with anti-digoxigenin antibodies coupled to peroxidase, and the brown reaction product was detected with DAB. For each experiment, nonspecific labeling was determined by omitting TdT. Few apoptotic cells were detected (arrows) $24 \mathrm{hr}$ after infection with HSV expressing wild-type $(A)$ or mutated (B) PS-1. An increased in apoptotic cells was observed in cells infected with HSV expressing APP-695 $(C)$. Cells infected with HSV/Lac $(D)$ or incubated with the vehicle $(E$, mock) show very few apoptotic cells.

Immunoblot analysis (Fig. 2B) demonstrated overexpression of full length PS-1 or A246E-PS-1 in primary neuronal cultures infected with an moi of 0.5 or 1 of the appropriate virus. Infection of parallel cultures with an HSV vector expressing the amyloid precursor protein APP-695 (Fig. $2 A$ ) demonstrated similar overexpression of APP-695.

\section{Cellular viability after infection with HSV recombinants}

To assess potential cytotoxicity in response to infection of neurons with HSV recombinants expressing $\beta$-galactosidase, PS-1, or A246-PS-1, cortical neurons infected at a range of moi were assayed for trypan blue exclusion and mitochondrial function. Cortical neurons infected with HSV/PS-1 or HSV/A246E-PS-1 and incubated with $0.2 \%$ trypan blue $24 \mathrm{hr}$ after infection showed no staining with the dye, which is taken up only by cells whose membrane is compromised (Fig. $3 A-F$ ). Trypan blue exclusion does not rule out apoptosis, because loss of membrane integrity occurs very late during apoptosis, but it does indicate that the cells are viable.

Further confirmation of the health of the cells is seen in the microscopic images (Fig. $3 A-C$ ), which show phase bright cells with long neuronal processes. In an independent assay for the viability of the $\mathrm{HSV}$-infected cells, we quantified cellular survival after HSV/PS-1 infection, using the 3-[4,5-dimethylthiozol-2-yl]- 2,5-diphenyl tetrazolium bromide metabolic assay. Neurons were infected in parallel with vehicle (mock) or with HSV vectors expressing wild-type or A246E-mutated PS-1, or LacZ, at moi of $0.1-5$ (Fig. $4 A-C$ ). No significant difference between groups in cellular survival was observed up to $72 \mathrm{hr}$. It can be concluded, therefore, that overexpression of wild-type or mutated PS-1 via HSV vectors is not sufficient to induce cell death in cortical neurons.

\section{Characterization of DNA damage in neurons infected with HSV recombinants}

We previously reported a form of DNA damage that is characterized by single-stranded DNA breaks, with no detectable double-stranded DNA breaks (Didier et al., 1996). Frequent single- and double-stranded DNA breaks are detected in DNA during apoptosis (Peitsch et al., 1993). Neurons with singlestranded DNA breaks are viable and may represent an earlier stage of apoptosis than neurons with double-stranded DNA fragmentation. We performed four different assays to determine whether PS-1 overexpression induces single- or double-stranded DNA breaks as seen in apoptosis.

The Klenow fragment of DNA polymerase is used in an assay that preferentially detects single-stranded DNA breaks (Rosl, 1992; Lauc et al., 1994). The polymerase binds to the exposed 


\section{Quantification of Apoptotic Cells by the TUNEL Method}

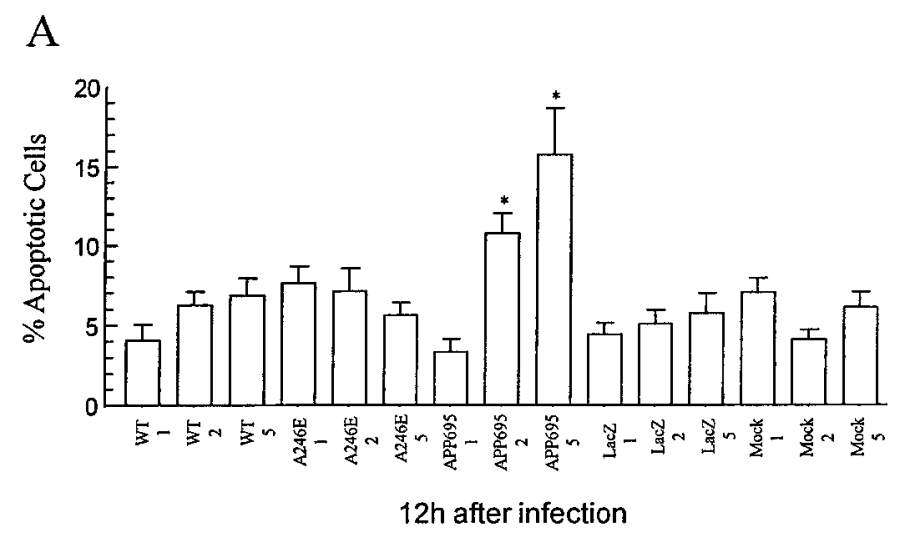

B

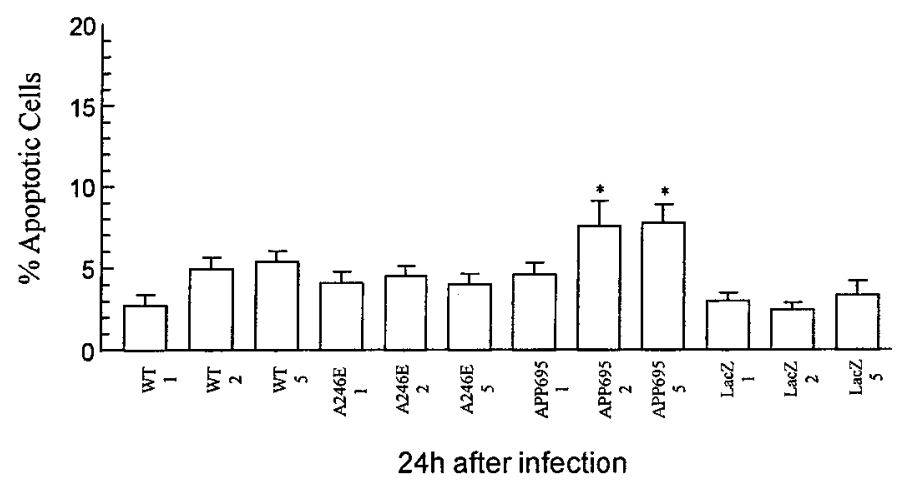

Figure 9. Quantification of the percentages of apoptotic cells shown in Figure 8. Apoptotic cells were counted as described in the legend to Figure 7. Enhanced apoptosis was not observed after infection of the neurons with HSV/PS-1 or HSV/A246E-PS-1, but it was observed when the cells were infected with HSV/APP-695. $A$, Twelve hours after infection; $B, 24 \mathrm{hr}$ after infection. The results are the average $\pm \mathrm{SEM}$ of counts from 10 microscopic fields with a total of $200-300$ cells counted per moi. $*$ denotes significance $(p<0.05)$ in the difference in values between cells infected with HSV/APP-695 and cells infected with HSV/Lac.

$3^{\prime}-\mathrm{OH}$ ends of DNA fragments that are generated when DNA strands are nicked, and it catalyzes the template-dependent addition of a mixture of biotin-labeled and unlabeled deoxynucleotides (Lauc et al., 1994). Cortical cultures that were infected for $24 \mathrm{hr}$ at an moi of 2 with HSV recombinants expressing wild-type or A246-mutated PS-1, or lacZ, or that were mock-infected, show few cells with detectable single-stranded DNA breaks, which are indicated by darkly stained nuclei (Fig. $5 A, B, D, E$ ). In sharp contrast, cells infected with HSV/APP695 show an increase in cells with apoptotic nuclei (Fig. $5 C$ ), despite the fact that their neuronal processes remain intact. These latter data are consistent with the recent report that overexpression of APP-695 in hippocampal neurons in vivo causes nuclear DNA fragmentation (Nishimura et al., 1998). Quantitative analyses of the data (Fig. 6A,B) confirm that overexpression of wild-type or A246E mutant PS-1 does not enhance apoptosis in cortical neurons, whereas apoptosis is increased significantly ( $p<0.05$; Bonferroni multiple $t$ test) in neurons infected with HSV/APP-695.

This lack of DNA fragmentation in PS-1-infected cells, and the enhanced apoptosis in cortical cells infected with HSV/APP695, was also seen when we used a DNA fragmentation enzyme immunoassay that detects histone-associated DNA fragments, thereby revealing internucleosomal degradation of genomic DNA that occurs during apoptosis (Compton, 1992; Pandey et al., 1994; Stewart, 1994; Allen et al., 1997). Neurons infected with HSV/ APP-695, but not neurons infected with the other HSV recombinant vectors, showed significant increases in DNA fragmentation $(p<0.05)$ (Fig. 7A,B).

TUNEL staining was also used to visualize apoptosis immunocytochemically (Gavrieli et al., 1992). This method, in contrast to the Klenow fragmentation assay, detects primarily doublestranded DNA breaks via terminal deoxynucleotidyl transferase (TdT) addition of deoxynucleotides to the $3^{\prime}-\mathrm{OH}$ ends of the DNA strands (Didenko and Hornsby, 1996; Didier et al., 1996). Cortical cells that were infected with HSV vectors expressing wild-type or A246E-mutated PS-1, or lacZ, or that were mockinfected show only a few TUNEL-positive cells (Fig. 8A,B,D,E), whereas cells infected with HSV/APP695 show numerous apoptotic nuclei (Fig. 8C). Quantification of the data revealed that a significant increase over control in the number of apoptotic cells was observed only in HSV/APP-695-infected cells $(p<0.05)$. Cultures infected with all other HSV recombinants showed no significant difference from control mock-infected cells in number of TUNEL-positive nuclei (Fig. 9A,B).

We further studied the nuclear morphology of cortical cells after infection with HSV recombinants by staining infected cells with bisbenzimide. Bisbenzimide binds to chromatin, allowing fluorescent visualization of normal and condensed chromatin (Bruner and Bursztajn, 1986). Morphologically, cells undergoing apoptosis show chromatin condensation, loss of nuclear envelope, and cellular fragmentation into apoptotic bodies (Cohen et al., 1992; Didier et al., 1996). The bisbenzimide assay yielded results similar to those obtained with the Klenow polymerase, DNA fragmentation, and TUNEL assays. Cortical cells that were infected with HSV vectors expressing wild-type PS-1, mutated (A246E) PS-1, or lacZ, or that were mock-infected show only few nuclei with altered morphology (Fig. 10A,B,D,E), whereas cells infected with HSV/APP-695 show an increase in the number of nuclei having condensed chromatin material (Fig. 10C). Quantitation of apoptotic cells detected with bisbenzimide showed that only cells infected with HSV/APP-695 have a significant increase in the number of apoptotic cells $24 \mathrm{hr}$ after infection (Fig. 11 $A, B$ ) ( $p<0.05$ by Bonferroni $t$ test).

Nucleosomal and cytoplasmic DNA isolated from the infected cells did not display an apoptotic ladder pattern when separated by agarose gel electrophoresis, even when a Southern blot using total mouse DNA as probe was performed to increase sensitivity (data not shown). The lack of detectable DNA laddering in the HSV/APP-695-infected cells suggests that this may not be as sensitive an assay for DNA fragmentation as the in situ assays that were used to detect apoptosis.

\section{Characterization of DNA damage in neurons infected with HSV recombinants and induced to undergo apoptosis}

To determine whether presenilins predispose to apoptosis, we tested the effect of overexpression of PS-1 or A246E-mutated PS-1 on neurons treated with the apoptosis-inducing agents etoposide and staurosporine (Fig. 12). Cortical cells were infected with HSV/PS-1, HSV/A246E-PS-1, or HSV/Lac at an moi of 2. Twelve hours later, the infected cells were exposed to $20 \mu \mathrm{M}$ 

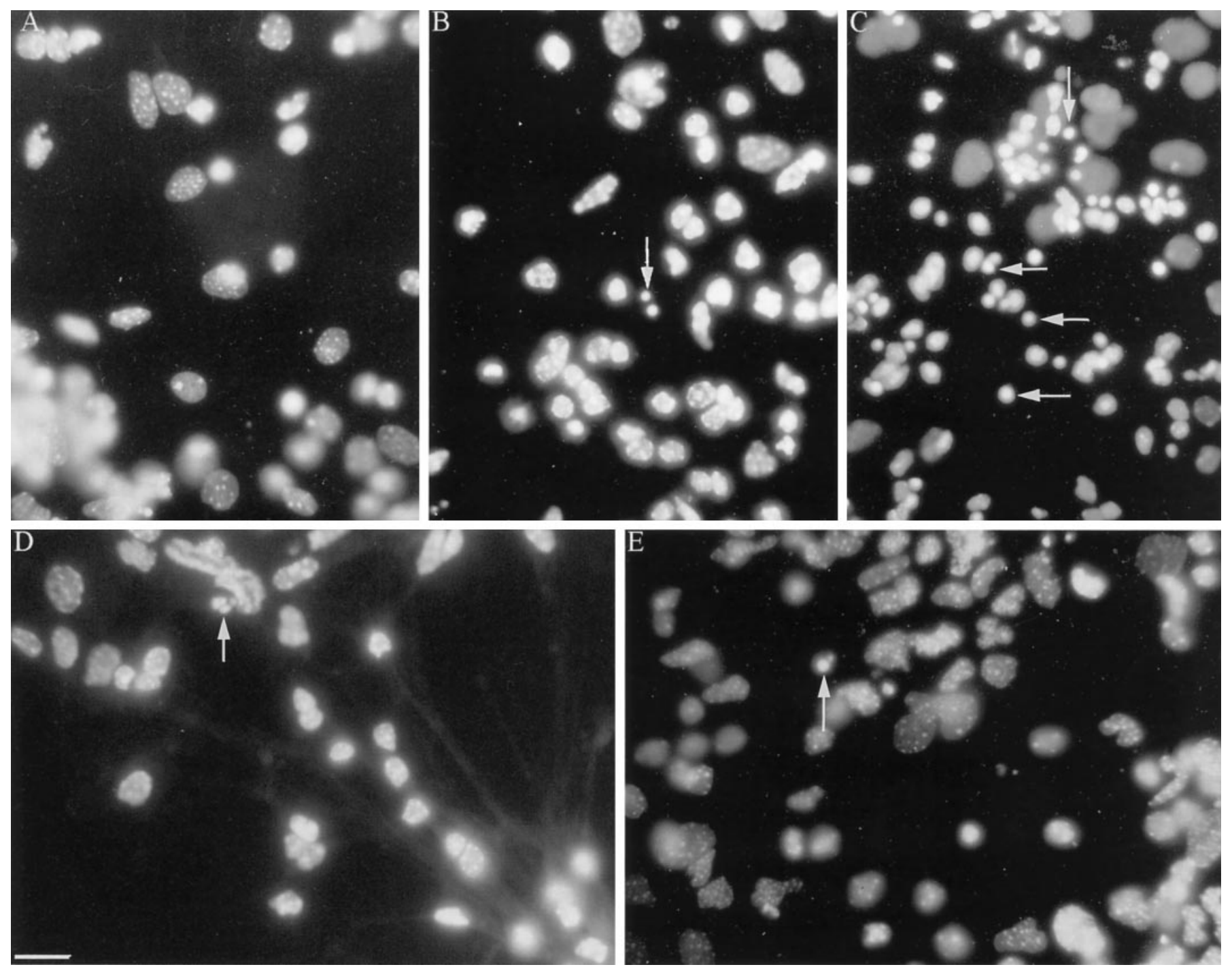

Figure 10. Bisbenzimide intercalates into DNA strands, allowing for fluorescent visualization of normal or condensed chromatin. Normal nuclei are regular in shape and round, whereas apoptotic nuclei (arrows) show condensation of chromatin material. Cortical cells infected with HSV/PS-1 (A) or HSV/A246E-PS-1 $(B)$ for $24 \mathrm{hr}$ at an moi of 2 show infrequent alterations in nuclear morphology. Cells infected with HSV/APP-695 ( $C$ ) show an increase in the number of nuclei with condensed chromatin material. Cells infected with HSV/Lac $(D)$ or incubated with vehicle alone $(E)$ show similar nuclear morphology as those infected with HSV/PS-1 or HSV/A246E-PS-1.

etoposide or $1 \mu \mathrm{M}$ staurosporine for $5 \mathrm{hr}$, after which the cells were evaluated with the DNA fragmentation enzyme immunoassay that detects histone-associated DNA fragments (Fig. 7e). Both etoposide and staurosporine induced a significant increase in DNA fragmentation in cortical cells that were mock-infected or infected with HSV/Lac. This increase in DNA fragmentation was prevented if the cells were infected with HSV/PS-1 or with HSV/A246E-PS-1 before being exposed to the apoptosisinducing agents.

\section{DISCUSSION}

Multiple laboratories have reported evidence for apoptosis, or programmed cell death, in pathological tissues obtained from the brains of Alzheimer's disease patients (Su et al., 1994; Guo et al., 1998). Therefore it is of interest that overexpression of FAD mutants of APP (Yamatsuji et al., 1996a,b; Giambarella et al., 1997; Zhao et al., 1997) or of wild-type APP itself [Nishimura et al. (1998); this report] causes increased apoptosis, and that overexpression of PS-1 and PS-2 in transfected cell lines results in an increased susceptibility to apoptosis (Deng et al., 1996; Guo et al., 1996; Wolozin et al., 1996), possibly by perturbing cellular calcium regulation and promoting oxidative stress (Guo et al., 1997, 1998).

The question of whether these genes induce apoptosis in primary neurons, however, has remained unanswered. PS-1 function may differ in primary neurons from cell lines. PS- 1 is reported to be expressed primarily in CNS neurons in the brain, suggesting that this protein may perform a neuron-specific function (Elder et al., 1996). In fact, in AD, neurons that express PS-1 antigen are less vulnerable to the disease than are neurons that do not express it (Giannakopoulos et al., 1997), and inhibition of PS-1 expression results in apoptosis (Roperch et al., 1998), suggesting a protective role for this protein. We therefore sought to determine whether overexpression of wild-type or A246E-mutated PS-1 induces DNA damage or apoptosis in primary mouse neurons in culture.

We used HSV vectors expressing wild-type or A246E-mutant PS-1, as well as wild-type APP-695 and appropriate controls, to 
Quantification of Apoptotic Cells Detected by Staining with Bis-Benzamide

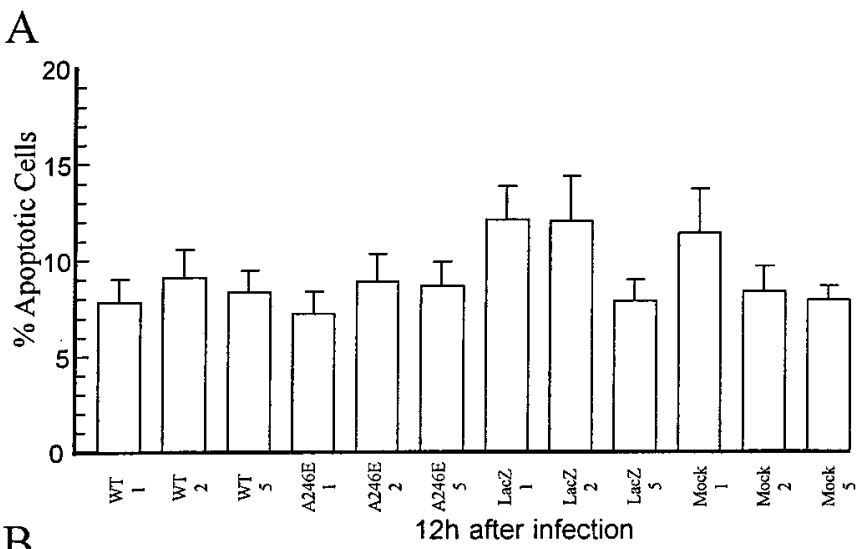

B

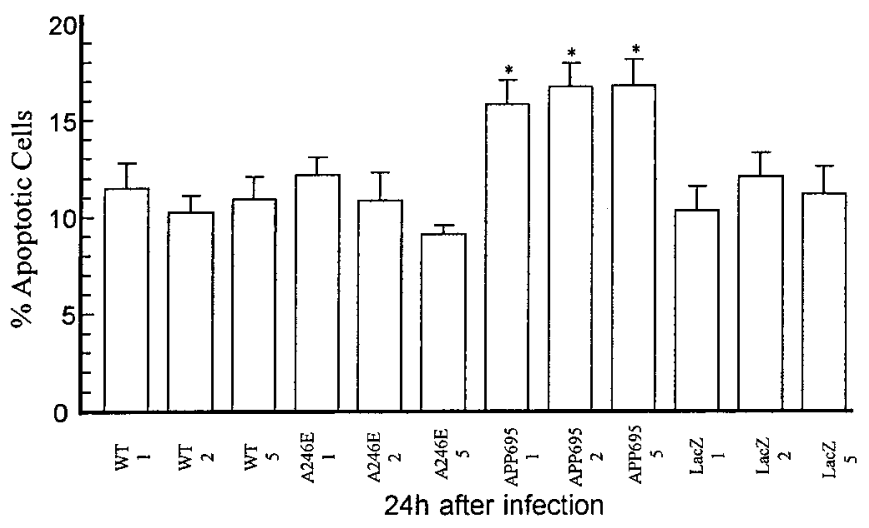

Figure 11. Quantification of apoptotic cells with bisbenzimide shows a lack of enhanced apoptosis $24 \mathrm{hr}$ after infection with HSV/PS-1 or HSV/A246E-PS-1. Enhanced apoptosis was observed $24 \mathrm{hr}$ after infection with HSV/APP-695 at an moi of 2. The total number of cells and the number of nuclei with condensed chromatin were counted in 10 random fields, and each value was expressed as the percentage of nuclei with condensed chromatin relative to the number of total nuclei counted. The results are the average \pm SEM. A total of 400-500 cells were counted for each moi. * denotes significance $(p<0.05)$ in the difference in values between cells infected with HSV/APP-695 and cells infected with HSV/ Lac. $A$, Twelve hours after infection; $B, 24 \mathrm{hr}$ after infection.

determine whether overexpression of these proteins leads to enhanced apoptosis in primary cortical neurons. We showed that cortical neurons infected with HSV vectors are viable and that when we infect at an moi of 2, the majority of the cortical neurons express the appropriate HSV-encoded protein. We also demonstrated that the overexpression of wild-type or A246E mutant PS-1 does not result in enhanced apoptosis. This was shown with four independent assays: (1) the Klenow DNA fragmentation assay for single-stranded DNA breaks; (2) a test to detect histoneassociated DNA fragments; (3) the TUNEL technique; and (4) bisbenzimide detection of chromatin condensation. Finally, we showed that overexpression of PS-1 or PS-1-A246E in cortical neurons suppresses apoptosis induced by etoposide or staurosporine.

In contrast to the results obtained with PS-1, overexpression of APP-695 in cortical neurons enhanced apoptosis. We tested APP695 for its effect on apoptosis in neurons, because this spliced form of APP is expressed preferentially in neurons (Neve et al.,

\section{Detection of DNA fragmentation after enhanced apoptosis.}

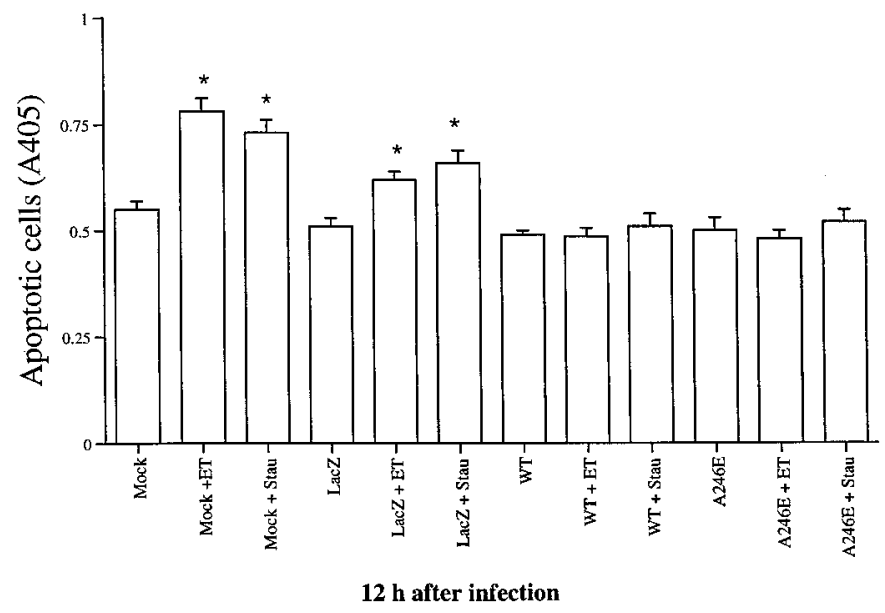

Figure 12. Expression of PS-1 or A246E-PS-1 in cortical neurons protects against apoptosis induced with etoposide or staurosporine. Twelve hours after infection of cortical cells with HSV/PS-1, HSV/A246E-PS-1, or HSV/Lac at an moi of 2, cells were exposed to etoposide $(E T, 20 \mu \mathrm{M})$ or staurosporine (Stau, $1 \mu \mathrm{M}$ ) for $5 \mathrm{hr}$. In an additional control, mockinfected cells were exposed to the same drugs. Samples were analyzed photometrically as described in Figure 7. Both etoposide and staurosporine induced a modest, albeit significant increase in DNA fragmentation in cortical cells $(p<0.05)$. This increase in DNA fragmentation was prevented if cells were infected with HSV/PS-1 or with HSV/A246E-PS-1 before being exposed to the apoptosis-inducing agents.

1988). In PC12 cells transfected with wild-type APP, TUNELpositive cells were increased almost twofold relative to controls (Zhao et al., 1997). We show that overexpression of APP in primary neurons gives an even greater enhancement of apoptosis over controls, a result consistent with the recent demonstration by Nishimura et al. (1998) that overexpression of wild-type APP-695 in rat neurons in vivo causes nuclear DNA fragmentation in transfected cells. Notably, the magnitude of APP-695-induced apoptosis was lower at $24 \mathrm{hr}$ than at $12 \mathrm{hr}$ after infection. Although we do not know the reason for this, it would be interesting to determine whether this decrease is caused by activity of cellular DNA repair mechanisms.

In contrast to results that have implicated presenilins in enhancing apoptosis or in rendering various cell lines more susceptible to apoptosis (Deng et al., 1996; Wolozin et al., 1996; Guo et al., 1997; Janicki and Monteiro, 1997), our results with cortical neurons show that overexpression of wild-type or A246E-mutated PS-1 is not sufficient by itself to induce apoptosis. In fact, overexpression of these proteins protects cortical neurons from experimentally induced apoptosis. However, at least 30 different missense mutations and one in-frame splice site mutation in PS-1 have been reported to cause FAD (Cruts et al., 1996), and we do not know whether all of these mutants are unable to induce apoptosis in primary neurons or whether they have a protective effect against apoptosis. In any case, the ability of PS- 1 to induce apoptosis appears to be cell-type specific, and this may have important implications for the pathogenesis in $\mathrm{AD}$, in which neurons are differentially affected.

\section{REFERENCES}

Allen RT, Hunter III WJ, Agrawal DK (1997) Morphological and biochemical characterization and analysis of apoptosis. J Pharmacol Toxicol Methods 37:215-228. 
Bredesen DE (1995) Neural apoptosis. Ann Neurol 38:839-851.

Bruner JM, Bursztajn S (1986) Acetylcholine receptor clusters are associated with nuclei in rat myotubes. Dev Biol 115:35-43.

Carlezon Jr WA, Boundy VA, Haile CN, Kalb RG, Neve RL, Nestler EJ (1997) Sensitization to morphine induced by viral-mediated gene transfer. Science 277:812-814.

Chow N, Korenberg JR, Chen X-N, Neve RL (1996) APP-BP1, a novel protein that binds to the carboxyl-terminal region of the amyloid precursor protein. J Biol Chem 271:11339-11346.

Cohen GM, Sun XM, Snowden RT, Dinsdale D, Skilleter DN (1992) Key morphological features of apoptosis may occur in the absence of internucleosomal DNA fragmentation. J Biochem 286:331-334.

Cohen GM, Sun XM, Snowden RT, Ormerod MG, Dinsdale D (1993) Identification of a transitional preapoptotic population of thymocytes. J Immunol 151:566-574.

Compton MM (1992) A biochemical hallmark of apoptosis: internucleosomal degradation of the genome. Cancer Metastasis Rev 11:105-119.

Cruts M, Hendriks L, Van Broeckhoven C (1996) The presenilin genes: a new gene family involved in Alzheimer disease pathology. Hum Mol Genet 5:1449-1455.

Deng G, Pike CJ, Cotman CW (1996) Alzheimer-associated presenilin-2 confers increased sensitivity to apoptosis in PC12 cells. FEBS Lett 397:50-54.

Didenko VV, Hornsby PJ (1996) Presence of double-strand breaks with single-base $3^{\prime}$ overhangs in cells undergoing apoptosis but not necrosis. J Cell Biol 135:1369-1376.

Didier M, Bursztajn S, Adamec E, Passani L, Nixon RA, Coyle JT, Wei JY, Berman SA (1996) DNA strand breaks induced by sustained glutamate excitotoxicity in primary neuronal cultures. J Neurosci 16:2238-2250.

Elder GA, Tezapsidis N, Carter J, Shioi J, Bouras C, Li HC, Johnson JM, Efthimiopoulos S, Friedrich Jr VL, Robakis NK (1996) Identification and neuron specific expression of the PS-1/presenilin I protein in human and rodent brains. J Neurosci Res 45:308-320.

Gavrieli Y, Sherman Y, Ben-Sasson SA (1992) Identification of programmed cell death in situ via specific labeling of nuclear DNA fragmentation. J Cell Biol 119:493-501.

Giambarella U, Yamatsuji T, Okamoto T, Matsui T, Ikezu T, Murayama Y, Levine MA, Katz A, Gautam N, Nishimoto I (1997) G protein $\beta \gamma$ complex-mediated apoptosis by familial Alzheimer's disease mutant of APP. EMBO J 16:4897-4907.

Giannakopoulos P, Bouras C, Kovari E, Shioi J, Tezapsidis N, Hof PR, Robakis NK (1997) Presenilin-1-immunoreactive neurons are preserved in late-onset Alzheimer's disease. Am J Pathol 150:429-436.

Greenberg ME, Ziff EB (1984) Stimulation of 3T3 cells induces transcription of the c-fos proto-oncogene. Science 311:433-436.

Guo Q, Furukawa K, Sopher BL, Pham DG, Robinson N, Martin GM, Mattson MP (1996) Alzheimer's PS-1 mutation perturbs calcium homeostasis and sensitizes PC12 cells to death induced by amyloid $\beta$-peptide. NeuroReport 8:379-383.

Guo Q, Sopher BL, Furukawa K, Pham DG, Robinson N, Martin GM, Mattson MP (1997) Alzheimer's presenilin mutation sensitizes neural cells to apoptosis induced by trophic factor withdrawal and amyloid beta peptide: involvement of calcium and oxyradicals. J Neurosci 17:4212-4222.

Guo Q, Fu W, Xie J, Luo H, Sells SF, Gedder JW, Bondada V, Rangnekar VM, Mattson MP (1998) Par-4 is a mediator of neuronal degeneration associated with the pathogenesis of Alzheimer disease. Nat Med 4:957-963.

Janicki S, Monteiro MJ (1997) Increased apoptosis arising from increased expression of Alzheimer's disease associated presenilin-2 mutation (N141I). J Cell Biol 139:485-495.

Lauc G, Perovic S, Dapper J, Flogel M, Iskric S, Muller WE (1994) A non-radioactive, sensitive method for the detection of DNA fragmentation in apoptotic cells. Anal Cell Pathol 7:107-114.
Levy-Lahad E, Wasco W, Poorkaj P, Romano DM, Oshima J, Pettingell WH, Yu CE, Jondro PD, Schmidt SD, Wang K, Crowley AC, Fu Y-H, Guenette SY, Galas D, Nemens E, Wigsman EM, Bird TD, Schellenberg GD, Tanzi RE (1995) Candidate gene for the chromosome 1 familial Alzheimer's disease locus. Science 269:973-977.

McPhie DL, Lee RKK, Eckman CB, Olstein DH, Durham SP, Yager D, Younkin SG, Wurtman RJ, Neve RL (1997) Neuronal expression of $\beta$-amyloid precursor protein Alzheimer mutations causes intracellular accumulation of a $\mathrm{C}$-terminal fragment containing both the amyloid $\beta$ and cytoplasmic domains. J Biol Chem 272:24743-24746.

Neve RL, Finch EA, Dawes LR (1988) Expression of the Alzheimer amyloid protein precursor gene transcripts in the human brain. Neuron 1:669-677.

Nishimura I, Uetsuki T, Dani SU, Ohsawa Y, Saito I, Okamura H, Uchiyama Y, Yoshikawa K (1998) Degeneration in vivo of rat hippocampal neurons by wild-type Alzheimer amyloid precursor protein overexpressed by adenovirus-mediated gene transfer. J Neurosci 18:2387-2398.

Pandey S, Walker PR, Sikorska M (1994) Separate pools of endonuclease activity are responsible for internucleosomal and high molecular mass DNA fragmentation during apoptosis. Biochem Cell Biol 72:625-629.

Peitsch MC, Muller C, Tschopp J (1993) DNA fragmentation during apoptosis is caused by frequent single-strand cuts. Nucleic Acids Res 21:4206-4209.

Rogaev EI, Sherrington R, Rogaeva EA, Levesque G, Ikeda M, Liang Y, Chi H, Lin C, Holman K, Tsuda T, Mar L, Sorbi S, Nacmias B, Piacentini S, Amaducci L, Chumakov I, Cohen D, Lannfelt L, Fraser PE, Rommens JM, St. George-Hyslop PH (1995) Familial Alzheimer's disease in kindreds with missense mutations in a gene on chromosome 1 related to the Alzheimer's disease type 3 gene. Nature 376:775-778.

Roperch JP, Alvaro V, Prieur S, Tuynder M, Nemani M, Lethrosne F, Piouffre L, Gendron MC, Israeli D, Dausset J, Oren M, Amson R, Telerman A (1998) Inhibition of presenilin 1 expression is promoted by 53 and p21WAF-1 and results in apoptosis and tumor suppression. Nat Med 4:835-838.

Rosl F (1992) A simple and rapid method for detection of apoptosis in human cells. Nucleic Acids Res 20:5243.

Sherrington R, Rogaev E, Liang Y, Rogaeva E, Levesque G (1995) Cloning of a gene bearing missense mutations in early-onset familial Alzheimer's disease. Nature 375:754-760.

Stewart BW (1994) Mechanisms of apoptosis: integration of genetic, biochemical, and cellular indicators. J Nat Cancer Inst 86:1286-1296.

Su JH, Anderson AJ, Cummings BJ, Cotman CW (1994) Immunohistochemical evidence for apoptosis in Alzheimer's disease. NeuroReport 20:2529-2533.

Thompson CB (1995) Apoptosis in the pathogenesis and treatment of disease. Science 267:1456-1462.

Wolozin B, Iwasaki K, Vito P, Ganjei JK, Lacana E, Sunderland T, Zhao B, Kusiak JW, Wasco W, D'Adamio L (1996) Participation of presenilin 2 in apoptosis enhanced basal activity conferred by an Alzheimer mutation. Science 274:1710-1713.

Yamatsuji T, Okamoto T, Takeda S, Murayama Y, Tanaka N, Nishimototo I (1996a) Expression of V642 APP mutant causes cellular apoptosis as Alzheimer trait-linked phenotype. EMBO J 15:498-509.

Yamatsuji T, Matsui T, Okamato T, Komatsuzaki K, Takeda S, Fukumoto H, Iwatsubo T, Suzuki N, Asami-Odaka A, Ireland S, Kinane TB, Giambarella U, Nishimoto I (1996b) G protein-mediated neuronal DNA fragmentation induced by familial Alzheimer's diseaseassociated mutants of APP. Science 272:1349-1352.

Zhao B, Chrest FJ, Horton Jr WE, Sisodia SS, Kusiak JW (1997) Expression of mutant amyloid precursor proteins induces apoptosis in PC12 cells. J Neurosci Res 47:253-263. 